\title{
Evaluation of the Use of Platelet-rich Fibrin Dressing in the Management of Free Gingival Graft Clinical Study
}

\author{
Elham Seaf ${ }^{1}$, Tarek Kasem², Ali A Sulaiman ${ }^{3}$
}

\begin{abstract}
Aim of the study: To evaluate the use of platelet-rich fibrin (PRF) dressing in the free gingival graft (FGG) recipient site by evaluating tissue healing and coverage of recession.

Materials and methods: The study included 40 patients having at least one site with Miller's class II recession to be treated via FGG. The participants were divided into two groups: PRF group consisted of 20 patients who had PRF dressing used over the FGG and Coe-Pak ${ }^{\mathrm{TM}}$ group

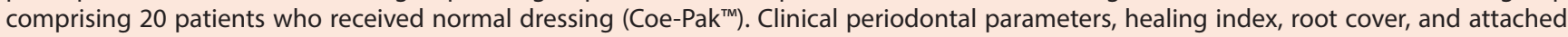
gingival width (AGW) were recorded prior to treatment and at 1 and 3 months postsurgery. A statistical analysis was performed to examine the differences between the study groups.

Results: The PRF group showed statistically significant differences in the level of healing index and root coverage.

Conclusion: It may be concluded, within the study limits, that PRF dressing plays important role in the process of FGG healing.

Clinical significance: Platelet-rich fibrin can be considered a useful reliable dressing.

Keywords: Free gingival graft, Gingival recession, Platelet-rich fibrin.

World Journal of Dentistry (2020): 10.5005/jp-journals-10015-1694
\end{abstract}

\section{INTRODUCTION}

Gingival recession (GR) can be one of the most challenging conditions for the periodontal surgeon. It can be defined as the displacement of the marginal gingiva apically with the exposure of the root surface. It has a common occurrence on the buccal surface of teeth. ${ }^{1}$ The resulting root exposure might contribute to dentin hypersensitivity, root caries, and, most importantly, esthetic distress. Gingival recession may be associated with morphological, functional, or inflammatory factors. ${ }^{2}$ Numerous surgical techniques have been suggested for the treatment of GR including free gingival grafts (FGGs), connective tissue graft (CTG), coronally advanced flap, laterally positioned flaps, guided tissue regeneration, acellular allograft, ${ }^{3}$ and PRF. 4

Free gingival graft is one of the most common periodontal plastic surgeries. It is utilized to increase or establish the attached gingiva around teeth and reduce the GR. The FGG was introduced by Sullivan and Atkins in 1968. It has been used widely to increase the attached gingiva and root coverage. However, the obvious disadvantage of poor color matching, the postoperative morbidity, ${ }^{5,6}$ and the average percentage of root coverage are the shortcomings of this technique. ${ }^{7}$

A variety of dressings have been used to protect the FGG, such as non-eugenol dressings. However, these conventional dressings act only as a mechanical barrier. ${ }^{8,9}$ However, biological dressings were introduced in the medical literature to enhance healing. Platelet-rich fibrin dressings have been used to treat skin ulcers and showed improved clinical results. ${ }^{10}$

Platelet-rich fibrin is the second generation of platelet concentrates that is obtained by a simple procedure. Platelet-rich fibrin clot contains several growth factors, leukocyte cytokines, and fibrin network establishment which are beneficial for wound closing and neovascularization. ${ }^{11,12}$ Several growth factors are found in PRF such as platelet-derived growth factor, vascular endothelial growth factor, transforming growth factors $\beta$, and epidermal growth factor.
${ }^{1-3}$ Department of Periodontology, Faculty of Dentistry, Damascus University, Damascus, Syrian Arab Republic

Corresponding Author: Elham Seaf, Department of Periodontology, Faculty of Dentistry, Damascus University, Damascus, Syrian Arab Republic, Phone: +963 994466527, e-mail: elhamseaf4@gmail.com

How to cite this article: Seaf E, Kasem T, Sulaiman AA. Evaluation of the Use of Platelet-rich Fibrin Dressing in the Management of Free Gingival Graft Clinical Study. World J Dent 2020;11(1):75-80.

Source of support: Nil

Conflict of interest: None

Platelet-rich fibrin is an adjuvant to enhance healing in the medical and dental literature. Platelet-rich fibrin has been used extensively in dentistry for socket preservation, sinus lift, periodontal regeneration, guided tissue regeneration, GR, and wound healing. ${ }^{13}$

Femminella et al. ${ }^{14}$ compared between PRF and a gelatin sponge in the management of palatal wounds and showed that the use of a PRF membrane as a palatal bandage is effective in accelerating palatal wound healing and reducing the patient's morbidity.

Desai et al. ${ }^{15}$ applied PRF over skin wound as a dressing and reported a nearly scarless esthetic wound healing.

The aim of this study was to evaluate the efficiency of using PRF when compared with non-eugenol-based dressings in the management of the FGG recipient site.

\section{Materials and Methods}

\section{Study Population}

This study was granted approval from the Institutional Ethics Committee at Damascus University. This study is registered at Clinical Trials (identifier: NCT03589235). 
A total of 40 patients who were referred to the Department of Periodontology, Faculty of Dentistry, Damascus University, were invited to participate in the study.

Subjects were included if they achieved the following criteria: Miller's class II localized GR and at least 1-2 mm of keratinized gingiva on the facial aspect of the involved tooth.

However, patients were excluded if they had any of the following cognitions: systematic diseases, pregnancy, behavioral factors (smoking habits), and dental and periodontal factors (having periodontal surgery on the experimental sites, inadequate endodontic treatment, orthodontic treatment, restorative materials, or tooth mobility at the site of surgery).

Finally, all participants gave their written consent after being informed about the nature of the study.

The participants were allocated randomly (toss of a coin) into two groups according to the dressing type used in the management of the FGG. Platelet-rich fibrin group comprised 20 patients (10 females and 10 males, mean age $=31$ years; Fig. 1). Non-eugenol $\left(\right.$ Coe-Pak ${ }^{\mathrm{TM}}$ ) group consisted of 20 patients ( 12 females and 8 males, mean age $=30$ years; Fig. 2).

Detailed medical and dental histories were collected, and a complete periodontal chart was recorded for each participant. The examined periodontal parameters included plaque index (PI), ${ }^{16}$ gingival index $(\mathrm{Gl}){ }_{1}^{17}$ bleeding on probing (BOP) index, probing depth (PD), ${ }^{18} \mathrm{AGW}$, and GR. ${ }^{19}$

\section{Surgical Procedure}

All patients received oral hygiene instructions and subsequently underwent periodontal debridement.

The recipient site was prepared similar to the technique described by Langer and Langer. ${ }^{20}$ In brief, a horizontal incision was made at the existing mucogingival junction (MGJ) with a \#15 blade, extending from interdental papillae mesially and distally of the GR area. Periosteum was left covering the bone at the coronal recipient site. The gingival tissue coronal to the horizontal incision was de-epithelialized. Wet gauze with saline was placed over the recipient bed until graft placement.

A graft measuring $1.5-2 \mathrm{~mm}$ in thickness was harvested from the area between the distal line angle of the maxillary canine and the mesial line of the first molar, located $\geq 2 \mathrm{~mm}$ away from the gingival margins. Strenuous effort was taken to make sure that all grafts are of similar size (15 mm length-10 mm width) with an even $2 \mathrm{~mm}$ of thickness. Later, the graft was positioned and stabilized with proper sutures ( 0.5 silk). Finally, two different dressings were applied over the graft to protect the graft.
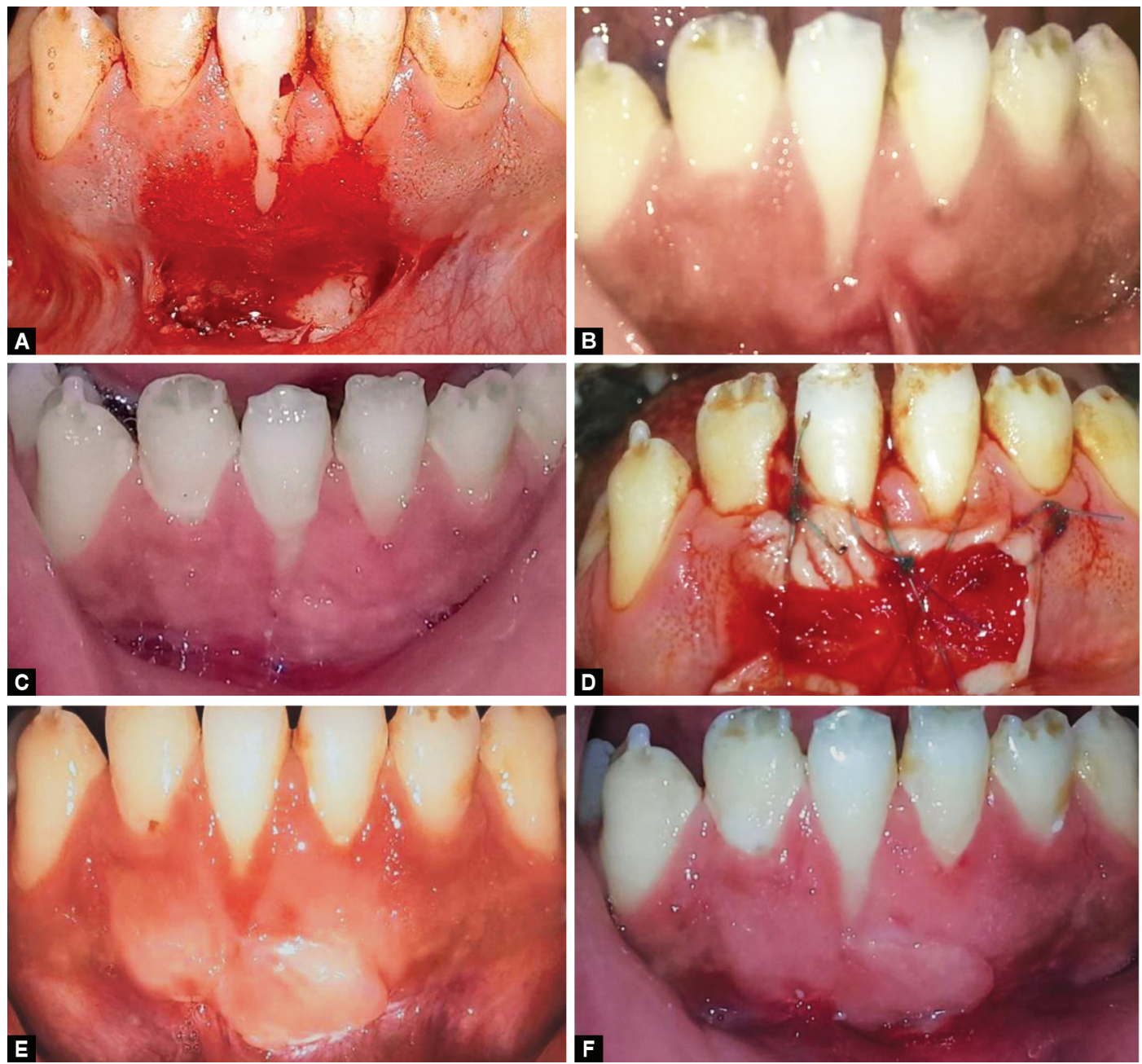

Figs 1A to F: Platelet-rich fibrin (PRF) group; (A) Gingival recession Miller's class II; (B) Recipient bed prepared; (C) Adaptation of the free gingival graft (FGG) at the recipient area, using PRF to cover FGG, suture tide; (D) Graft healing at 10th day; (E) 1 month; (F) 3 months postsurgery 

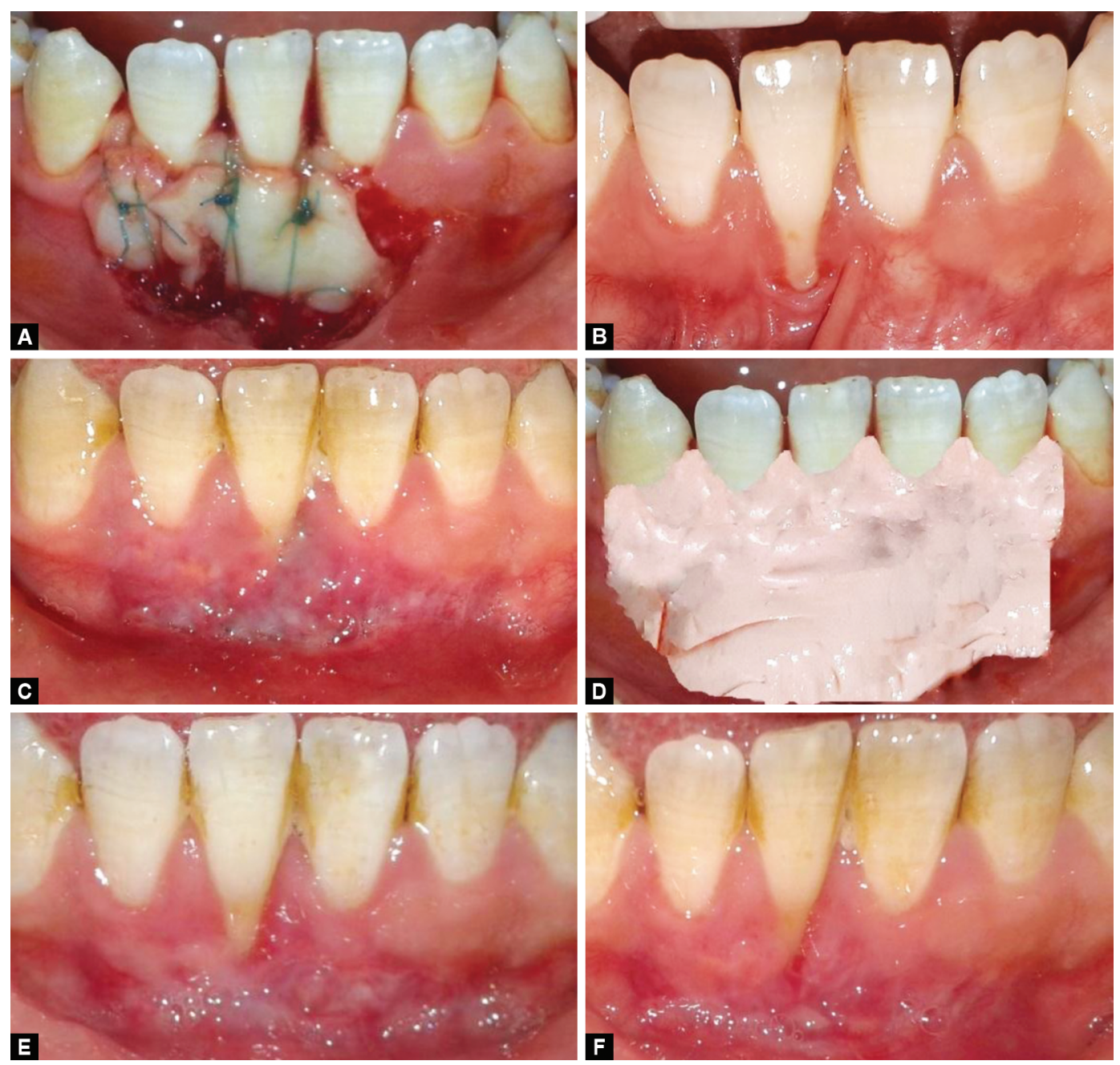

Figs 2A to F: Coe-Pak' ${ }^{\mathrm{TM}}$ group; (A) Gingival recession Miller's class II; (B) Adaptation of the FGG at the recipient area, suture tide; (C) Using Coe-Pak ${ }^{\mathrm{TM}}$ dressing to cover FGG; (D) Graft healing at 10th day; (E) 1 month; (F) 3 months postsurgery

\section{PRF Group}

A $10 \mathrm{~mL}$ blood sample was taken by venipuncture of the antecubital vein from each patient; it was divided into two sterile tubes of $5 \mathrm{~mL}$ each. Immediately, the tubes were centrifuged at 3,000 rpm for 10 minutes. The fibrin membranes were obtained by squeezing the clot with dry gauze to use it as a PRF dressing over the FGG represented. Properly suitable sutures were used to stabilize the PRF dressing over the FGG recipient site.

\section{Coe-Pak ${ }^{\mathrm{TM}}$ Group}

The Coe-Pak ${ }^{\mathrm{TM}}$ dressing was prepared according to the manufacturer's instructions. Then, the paste was modern into a roll. Eventually, the roll was applied over the graft, and a gentle pressure was used to stabilize the dressing into the interdental spaces. Overextension of the dressing onto uninvolved mucosa should be avoided.

\section{Postoperative Care}

Postoperative care instructions were given to the patients. Medications prescribed were amoxicillin 500 mg bid for 1 week, $0.12 \%$ chlorhexidine mouthwash, and an anti-inflammatory analgesic. The patients were instructed to mouthwash gently twice daily for 3 weeks. Toothbrushing activities in the surgical sites were discontinued. All patients had uneventful recoveries with no complications reported. Sutures were removed 10-15 days postsurgery.

\section{Postsurgical Screening}

Measurement of the FGG healing index was performed on the 10th day and 1 month postsurgery.

Clinical periodontal parameters (GR, AGW, PI, GI, BOP, and PD) were scored at baseline, 1 month, and 3 months after graft placement.

\section{Statistical Analysis}

Statistical testing was employed using SPSS (version 21, Chicago, IL, USA). A descriptive analysis was conducted (standard deviation, mean, and frequency distribution) for the collected data. The Wilcoxon test was used to analyze the differences over time in the same group. The Mann-Whitney $U$ test was used to assess intragroup comparisons. Data were considered statistically significant at level $<0.05$.

\section{Results}

The characteristics of the patient sample are presented in Table 1. The mean PI, BOP, and PD for the PRF and Coe-Pak ${ }^{\mathrm{TM}}$ groups at baseline and 3 months postsurgery are presented in Table 2. 
There were no statistically significant differences in periodontal parameters scores (PI, BOP, PD, GR, and AGW) between the study groups at the baseline examination (Tables 2 and 3). No significant differences were found at the 3-month postsurgery interval between PRF and Coe-Pak ${ }^{\mathrm{TM}}$ groups regarding $\mathrm{PI}, \mathrm{BOP}$, and PD.

Table 3 demonstrates the changes in GR and AGW at baseline, 1 month, and 3 months postsurgery. There were significant reduction in GR at the 1- and 3-month postsurgery intervals in both the PRF and Coe-Pak ${ }^{\mathrm{TM}}$ groups compared with baseline measures $(p=0.001)$. Similarly, the two groups showed a significant improvement in AGW at the 3-month interval $(p=0.001)$. Likewise, no significant differences were found at the 1- or 3-month postsurgery interval between PRF and Coe-Pak ${ }^{\mathrm{TM}}$ groups $(p>0.05)$.

The root coverage at 1 month postsurgery increased significantly $(p=0.004)$ from $(1.20 \pm 0.52 \mathrm{~mm})$ in the PRF group compared with that $(0.60 \pm 0.68 \mathrm{~mm})$ in the Coe-Pak ${ }^{\mathrm{TM}}$ group. Similarly, at 3 months, there was a highly significant improvement in the PRF group $(1.80 \pm 0.77 \mathrm{~mm})$ compared with the Coe-Pak ${ }^{\mathrm{TM}}$ group ( $1.20 \pm 0.83 \mathrm{~mm} ; p=0.02 ;$ Table 4$)$.

The increase in the gain of AGW was statistically significant. The mean gain was greater in the PRF group than in the Coe-Pak ${ }^{\mathrm{TM}}$ group at 1 month postsurgery $(p=0.02)$. However, Table 4 showed that there was no significant difference noticeable between the two groups at 3 months posttreatment $(p>0.05)$.

Finally, the data in Table 5 show that healing in the PRF group at 10 days postsurgery improved significantly as opposed to the Coe-Pak ${ }^{T M}$ group $(p=0.004)$.

Table 1: Demographic characteristics of the study groups

\begin{tabular}{llll}
\hline & & PRF group & Coe-Pak $^{\text {TM }}$ group \\
\hline$n$ & & 20 & 20 \\
Gender, $n(\%)$ & Male & $10(50)$ & $8(40)$ \\
& Female & $10(50)$ & $12(60)$ \\
\multicolumn{2}{l}{ Age (years; mean \pm SD) } & $31 \pm 7$ & $30 \pm 8$ \\
\multicolumn{2}{l}{ Age range (years) } & $20-42$ & $18-42$ \\
\hline
\end{tabular}

$\mathrm{SD}$, standard deviation

\section{Discussion}

Biological dressings have been used to enhance the healing process and minimize the patient's discomfort of the palatal open wound. Authors have investigated the usefulness of biological dressings in the management of hard and soft tissues in periodontal surgery. Platelet-rich fibrin clot plays an important role in accelerating healing in the medical and dental literature. Results obtained from clinical trials have evaluated the effect of PRF dressing in the management of the FGG's palatal wound, suggesting that it reduced postoperative morbidity of the palatal wound.

To the best of our knowledge, this study is the first clinical trial to evaluate the efficiency of the use of PRF as a dressing over the FGG.

This study showed significantly improved healing $(p<0.05)$ among patients who had FGG + PRF in comparison with Coe-Pak ${ }^{\mathrm{TM}}$ particularly at the 10th day. These findings were in accordance with previously reported data in the literature regarding the use of PRF. In a recent case report, Ibraheem ${ }^{21}$ showed that the use of a PRF membrane is effective in accelerating the healing of FGG in treating soft tissue defects preceding implant placement and in increasing the keratinized tissue. Femminella et al. ${ }^{14}$ and Ozcan et al. ${ }^{22}$ used PRF bandage to reduce complaints due to the palatal donor site wound and demonstrated that PRF accelerates palatal wound healing and reduces the patient's morbidity. On a parallel note, Desai et al. used PRF over skin wounds in the lower lip region and reported enhancement of wound healing and minimization of scars.

Furthermore, the mean percentage of root coverage increased significantly $(p<0.05)$ at 1 and 3 months postsurgery (35.48 and $58.06 \%$ for PRF, when compared with 20.69 and $34.48 \%$ for Coe$\left.\mathrm{Pak}^{\mathrm{TM}}\right)$.

This finding was not in line with the data of Jahnke et al. ${ }^{23}$ who compared between FGG and CTG for root coverage in Miller's class I and class II recessions and revealed a $43 \%$ root coverage percentage with FGG at both periods (after 3 and 6 months).

In addition, this study revealed that the gain of AGW increased significantly $(p=0.02)$ in the PRF group compared with the CoePak $^{\mathrm{TM}}$ group ( $5.25 \pm 0.72 \mathrm{~mm}$ and $4.65 \pm 0.87 \mathrm{~mm}$, respectively) at the 1-month and ( $4.85 \pm 0.81 \mathrm{~mm}$ and $4.30 \pm 0.92 \mathrm{~mm}$, respectively) 3-month postsurgery intervals.

Table 2: Mean clinical parameters in the study groups at baseline and 3 months postsurgery

\begin{tabular}{|c|c|c|c|c|c|c|c|}
\hline & \multicolumn{3}{|c|}{ At baseline } & \multicolumn{4}{|c|}{ At 3 months } \\
\hline & PRF group & Coe-Pak ${ }^{\mathrm{TM}}$ group & $p$ value & PRF group & $p$ value & Coe-Pak ${ }^{\mathrm{TM}}$ group & $p$ value \\
\hline $\mathrm{PI}(\% ;$ mean \pm SD) & $0.27 \pm 0.17$ & $0.23 \pm 0.08$ & 0.13 & $0.16 \pm 0.14$ & 0.001 & $0.09 \pm 0.08$ & 0.001 \\
\hline Gl (\%; mean \pm SD) & $0.23 \pm 0.16$ & $0.16 \pm 0.08$ & 0.06 & $0.09 \pm 0.09$ & 0.001 & $0.04 \pm 0.07$ & 0.001 \\
\hline $\mathrm{BOP}(\% ;$ mean $\pm \mathrm{SD})$ & $6.06 \pm 3.73$ & $3.49 \pm 3.35$ & 0.08 & $3.56 \pm 3.4$ & 0.005 & $1.93 \pm 1.94$ & 0.003 \\
\hline $\mathrm{PD}(\mathrm{mm} ;$ mean $\pm \mathrm{SD})$ & $1.20 \pm 0.41$ & $1.15 \pm 0.37$ & 0.68 & $1.15 \pm 0.37$ & 0.046 & $1.00 \pm 0.00$ & 0.083 \\
\hline
\end{tabular}

Table 3: Mean gingival recession and attached gingival width in the platelet-rich fibrin and Coe-Pak ${ }^{\mathrm{TM}}$ groups at baseline, 1 month, and 3 months postsurgery $(n=40)$

\begin{tabular}{|c|c|c|c|c|c|c|c|c|}
\hline \multirow{3}{*}{$\begin{array}{l}\text { Parameter } \\
\text { GR }\end{array}$} & \multirow{3}{*}{$\begin{array}{l}\text { Study group } \\
\text { PRF group }\end{array}$} & \multirow{3}{*}{$\begin{array}{l}\text { Baseline } \\
\text { Mean } \pm S D \\
3.10 \pm 1.41\end{array}$} & \multicolumn{3}{|c|}{1 month postsurgery } & \multicolumn{3}{|c|}{3 months postsurgery } \\
\hline & & & \multirow{2}{*}{$\begin{array}{c}\text { Mean } \pm S D \\
1.90 \pm 1.02\end{array}$} & \multicolumn{2}{|c|}{$p$ value $e^{*}$} & \multirow{2}{*}{$\begin{array}{c}\text { Mean } \pm S D \\
1.30 \pm 0.86\end{array}$} & \multicolumn{2}{|c|}{ pvalue* } \\
\hline & & & & 0.001 & 0.31 & & 0.001 & 0.20 \\
\hline & Coe-Pak ${ }^{T M}$ group & $2.90 \pm 1.55$ & $2.30 \pm 1.22$ & 0.001 & & $1.90 \pm 1.33$ & 0.003 & \\
\hline \multirow[t]{2}{*}{ AGW } & PRF group & $1.55 \pm 0.83$ & $6.70 \pm 0.66$ & 0.001 & 0.14 & $6.35 \pm 0.75$ & 0.001 & 0.64 \\
\hline & Coe-Pak ${ }^{\mathrm{TM}}$ group & $1.75 \pm 1.00$ & $6.40 \pm 0.50$ & 0.001 & & $6.25 \pm 0.55$ & 0.001 & \\
\hline
\end{tabular}

*Mann-Whitney $U$ 
Table 4: Mean change in gingival recession and attached gingival width in the platelet-rich fibrin and Coe-Pak ${ }^{\mathrm{TM}}$ groups at (baseline-1 month postsurgery) and (baseline- 3 months postsurgery) $(n=40)$

\begin{tabular}{|c|c|c|c|c|c|c|c|}
\hline \multirow[b]{2}{*}{ Variable studied } & \multirow[b]{2}{*}{ Study group } & \multicolumn{3}{|c|}{ Baseline - 1 month } & \multicolumn{3}{|c|}{ Baseline-3 months } \\
\hline & & Mean $\pm S D$ & $\%$ & $p$ value* & Mean $\pm S D$ & $\%$ & $p$ value \\
\hline \multirow[t]{2}{*}{ Change in GR } & PRF group & $1.20 \pm 0.52$ & 35.48 & 0.004 & $1.80 \pm 0.77$ & 58.06 & 0.02 \\
\hline & 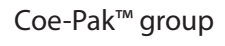 & $0.60 \pm 0.68$ & 20.69 & & $1.20 \pm 0.83$ & 34.48 & \\
\hline \multirow{2}{*}{$\begin{array}{l}\text { Change in AGW } \\
\text { (1 month) }\end{array}$} & PRF group & $5.25 \pm 0.72$ & & 0.02 & $4.85 \pm 0.81$ & & 0.06 \\
\hline & Coe-Pak ${ }^{\mathrm{TM}}$ group & $4.65 \pm 0.87$ & & & $4.30 \pm 0.92$ & & \\
\hline
\end{tabular}

Change in GR, root coverage; change in AGW, gain in attached gingival width

${ }^{*}$ Mann-Whitney $U$

Table 5: Comparison of the healing index in the two groups between the two study periods $(n=40)$

\begin{tabular}{|c|c|c|c|c|c|c|c|c|c|c|}
\hline & Period & Study groups & \multicolumn{2}{|c|}{ Mean $\pm S D$} & $p$ value* & Period & \multicolumn{2}{|c|}{ Study groups } & Mean $\pm S D$ & $p$ value ${ }^{*}$ \\
\hline \multirow[t]{2}{*}{ Healing index } & \multirow[t]{2}{*}{ 10th day } & PRF & & $5 \pm 0.51$ & 0.004 & 1 month & \multicolumn{2}{|c|}{ PRF } & $5.0 \pm 0.0$ & \multirow[t]{2}{*}{1.00} \\
\hline & & Coe-Pak $^{\text {TM }}$ & \multicolumn{2}{|c|}{$2.70 \pm 0.18$} & & & \multicolumn{2}{|c|}{ Coe-Pak ${ }^{\mathrm{TM}}$} & $5.0 \pm 0.0$ & \\
\hline & \multicolumn{2}{|c|}{ Verypoor } & \multicolumn{2}{|r|}{ Poor } & \multicolumn{2}{|r|}{ Good } & \multicolumn{2}{|c|}{ Verygood } & \multicolumn{2}{|c|}{ Excellent } \\
\hline Study groups & $P R F$ & Coe-Pak ${ }^{\mathrm{TM}}$ & $P R F$ & Coe-Pak ${ }^{\mathrm{TM}}$ & $P R F$ & Coe-Pak ${ }^{\mathrm{TM}}$ & $P R F$ & Coe-Pak ${ }^{\mathrm{TM}}$ & $P R F$ & Coe-Pak ${ }^{\mathrm{TM}}$ \\
\hline \multirow[t]{2}{*}{ Healing at 10 days } & 0 & 0 & 0 & 9 & 11 & 7 & 9 & 4 & 0 & 0 \\
\hline & $0 \%$ & $0 \%$ & $0 \%$ & $45 \%$ & $55 \%$ & $35 \%$ & $45 \%$ & $20 \%$ & $0 \%$ & $0 \%$ \\
\hline
\end{tabular}

*Mann-Whitney $U$

Silva et al. ${ }^{24}$ reported AGW after assessing FGG dimensions in the mandibular incisor area in smokers and nonsmokers $(4.7 \pm 1.0$ $\mathrm{mm}$ at 1 month and $4.4 \pm 1.0 \mathrm{~mm}$ at 3 months).

Jenabian et al. ${ }^{25}$ compared the use of gingival unit graft with FGG for treatment of localized GR and showed measured AGW was $4.68 \pm 1.43 \mathrm{~mm}$ at 1 month postsurgery and $3.72 \pm 1.52 \mathrm{~mm}$ at 3 months.

Several periodontal dressings have been employed in periodontal surgeries; nonetheless, no attempts have been made previously made to use PRF as a dressing over gingival grafts. ${ }^{8}$ These dressings demonstrated satisfactory clinical results, but their ability to assist healing has been largely through mechanical protection of the wound area. Despite Coe-Pak ${ }^{\mathrm{TM}}$ dressing used in our study being eugenol free and, thus, without any irritant that might cause any inflammation or pain, it has very little biological effect on the recipient region tissues. ${ }^{8,14}$ Hence, its principal function is to cover the graft and act as a mechanical barrier so as to ensure uncomplicated healing.

On a parallel note, data from this study yielded the clear advantage for PRF dressing in comparison with Coe-Pak ${ }^{\mathrm{TM}}$ dressing. The clinical outcomes of this study can be explained in the light of the properties of PRF.

First, the growth factors encompassed with the PRF are involved in promoting cell mitosis and induction of cell differentiation. In addition, the fibrin mesh acts as a scaffold supporting the growth factor and cytokines aggregation and facilitating their long-term release. Consequently, this will enhance the advancement of the healing process. ${ }^{12,14}$

Second, it enmeshes glycosaminoglycans from the blood and platelets, which have a great capacity to support cell migrations and healing processes. ${ }^{14}$

Third, PRF is an immune and platelet concentrate that collects on a single fibrin membrane.

The PRF membranes simultaneously support the development of the three keys to healing and soft tissue maturation, namely angiogenesis, immunity, and epithelial cover. ${ }^{15}$
This membrane protects open wounds and accelerates healing, favors the development of microvascularization, and guides epithelial cell migration to its surface. Furthermore, this matrix contains leukocytes. Although platelet and leukocyte cytokines are important in the biology of this biomaterial, the real therapeutic potential of PRF can be determined by the fibrin matrix supporting them. ${ }^{15}$ Therefore, its utilization seems to be of high significance in the case of infected wounds and as a protective dressing over an FGG.

Finally, PRFs are easy to obtain, cheap, and require little preparation time and effort.

\section{Conclusion}

Based on the results obtained from this study, it can be concluded that utilizing PRF dressing over an FGG resulted in more root coverage and improved healing compared with using Coe-Pak ${ }^{\mathrm{TM}}$ dressing. Thus, it is suggested that PRF can be considered a useful reliable dressing.

\section{References}

1. Serino $G$, Wennstrom $J L$, Lindhe J, et al. The prevalence and distribution of gingival recession in subjects with a high standard of oral hygiene. J Clin Periodontol 1994;21(1):57-63. DOI: 10.1111/j.1600051X.1994.tb00278.x.

2. Dominiak M, Gedrange T. New perspectives in the diagnostic of gingival recession. Adv Clin Exp Med 2014;23(6):857-863. DOI: 10.17219/acem/27907.

3. Aichelmann-Reidy ME, Yukna RA, Evans GH, et al. Clinical evaluation of acellular allograft dermis for the treatment of human gingival recession. J Periodontol 2001;72(8):998-1005. DOI: 10.1902/ jop.2001.72.8.998.

4. Jankovic S, Aleksic Z, Klokkevold P, et al. Use of platelet-rich fibrin membrane following treatment of gingival recession: a randomized clinical trial. Int J Periodontics Restorative Dent 2012;32(2):e41-e50.

5. Keceli HG, Aylikci BU, Koseoglu S, et al. Evaluation of palatal donor site haemostasis and wound healing after free gingival graft surgery. J Clin Periodontol 2015;42(6):582-589. DOI: 10.1111/jcpe.12404. 
6. Curtis Jr JW, McLain JB, Hutchinson RA. The incidence and severity of complications and pain following periodontal surgery. J Periodontol 1985;56(10):597-601. DOI: 10.1902/jop.1985.56.10.597.

7. Cortellini P, Pini Prato G. Coronally advanced flap and combination therapy for root coverage. Clinical strategies based on scientific evidence and clinical experience. Periodontol 2000 2012;59(1): 158-184. DOI: 10.1111/j.1600-0757.2011.00434.x.

8. Rubinoff $\mathrm{CH}$, Greener EH, Robinson PJ. Physical properties of periodontal dressing materials. J Oral Rehabil 1986;13(6):575-586. DOI: 10.1111/j.1365-2842.1986.tb00681.x.

9. Shanmugam M, Kumar T, Arun K, et al. Clinical and histological evaluation of two dressing materials in the healing of palatal wounds. J Indian Soc Periodontol 2010;14(4):241-244. DOI: 10.4103/0972124X.76929.

10. Cieslik-Bielecka A, Choukroun J, Odin G, et al. L-PRP/L-PRF in esthetic plastic surgery, regenerative medicine of the skin and chronic wounds. Curr Pharm Biotechnol 2012;13(7):1266-1277. DOI: 10.2174/138920112800624463.

11. Choukroun J, Adda F, Schoeffler C, et al. Une opportunité en paroimplantologie: Le PRF. Implantodontie; 2001;42:55-62.

12. Gaultier F, Navarro G, Donsimoni J, et al. Platelet concentrates. Part 3: clinical applications. Implantodontie 2004;13(1):3-11. DOI: 10.1016/ j.implan.2003.11.002.

13. Borie $E$, Oliví DG, Orsi IA, et al. Platelet-rich fibrin application in dentistry: a literature review. Int J Clin Exp Med 2015;8(5):7922-7929.

14. Femminella B, laconi MC, Di Tullio M, et al. Clinical comparison of platelet-rich fibrin and a gelatin sponge in the management of palatal wounds after epithelialized free gingival graft harvest: a randomized clinical trial. J Periodontol 2016;87(2):103-113. DOI: 10.1902/jop.2015.150198.

15. Desai CB, Mahindra UR, Kini YK, et al. Use of platelet-rich fibrin over skin wounds: modified secondary intention healing. J Cutan Aesthet Surg 2013;6(1):35-37. DOI: 10.4103/0974-2077.110096.
16. Silness J, Loe H. Periodontal disease in pregnancy. II. Correlation between oral hygiene and periodontal condition. Acta Odontol Scand 1964;22:121-135. DOI: 10.3109/00016356408993968.

17. Loe H, Silness J. Periodontal disease in pregnancy. I. Prevalence and severity. Acta Odontol Scand 1963;21:533-551. DOI: 10.3109/00016356309011240.

18. Papapanou NP, Lindhe J. Examination of patients with periodontal disease. In: Lindhe J, Lang NP, Karring T, ed., Clinical periodontology and implant dentistry, 5th ed., Blackwell Munksgaard; 2008. pp. 573-586.

19. Miller Jr P. A classification of marginal tissue recession. Int J Periodont Rest Dent 1985;5(2):8-13.

20. Langer B, Langer L. Subepithelial connective tissue graft technique for root coverage. J Periodontol 1985;56(12):715-720. DOI: 10.1902/ jop.1985.56.12.715.

21. Ibraheem W. Effect of platelet-rich fibrin and free gingival graft in the treatment of soft tissue defect preceding implant placement. J Contemp Dent Pract 2018;19(7):895-899. DOI: 10.5005/ jp-journals-10024-2353.

22. Ozcan M, Ucak O, Alkaya B, et al. Effects of Platelet-Rich Fibrin on Palatal Wound Healing After Free Gingival Graft Harvesting: A Comparative Randomized Controlled Clinical Trial. Int J Periodontics Restorative Dent 2017;37(5):e270-e278.

23. Jahnke PV, Sandifer JB, Gher ME, et al. Thick free gingival and connective tissue autografts for root coverage. J Periodontol 1993;64(4):315-322. DOI: 10.1902/jop.1993.64.4.315.

24. Silva CO, Ribeiro ÉDP, Sallum AW, et al. Free gingival grafts: graft shrinkage and donor-site healing in smokers and nonsmokers. J Periodontol 2010;81(5):692-701. DOI: 10.1902/jop.2010. 090381.

25. Jenabian N, Bahabadi MY, Bijani A, et al. Gingival unit graft vs free gingival graft for treatment of gingival recession: a randomized controlled clinical trial. J Dent (Tehran) 2016;13(3):184-192. 